\title{
Santa María la Antigua del Darién
}

\section{Escribe: JOSE RESTREPO POSADA}

En los años que siguieron al descubrimiento, los españoles se establecieron en las islas: Santo Domingo, Cuba; pero poco a poco fueron extendiendo sus dominios hacia el mediodía y comenzaron a poblar lo que apellidaban "tierra firme" o sea lo que hoy llamamos América del Sur.

El sistema de colonización era bastante curioso; trataban, por decirlo así, de construír una ciudad parecida a una de la península (con los necesarios cambios) dotada de un gobierno militar y civil, de un ejército que la protegiera de las incursiones de los indígenas y la poblaban con una colonia española que le diera vida. Esta ciudad era la base para que se fueran extendiendo poco a poco las conquistas: $y$ no de otro modo era el sistema en lo espiritual; se constituía una diócesis; su capital se dotaba de suficiente clero, $y$ en la parte material, de lujosos paramentos: así se formaba la vida cristiana en los españoles a quienes la dura conquista había necesariamente hecho perder ciertos sentimientos de humanidad, y de allí salía el clero que acompañando a los expedicionarios, evangelizaría a los indígenas, razón ética única que justificaba la ocupación de estos territorios la corona española. El primer centro de esta evangelización en nuestra patria fue Santa María la Antigua del Darién. Confiado el Rey Católico en que esta ciudad, fundada por Balboa en 1510 al costado occidental del golfo de Urabá, a la orilla del río Tanela, sería un verdadero centro irradiador, pidió al Papa León X, la erigiera como diócesis, y el Sumo Pontífice así lo hizo el 28 de agosto de 1513. Fue esta la primera diócesis erigida en los dominios españoles del continente americano $\mathrm{y}$ es en un rincón olvidado de nuestra patria donde funcionó por primera vez una organización operante dentro de la Iglesia (1).

Veamos someramente la forma como se dotó esta diócesis; su efímera vida y sus, en apariencia, desconsoladores resultados.

Don fray Juan de Quevedo, religioso franciscano fue el primer obispo de Santa María la Antigua, natural de Vejoris (Santander), sus padres se

(1) Historia documentada de la iglesia de Urabá y Darién por fray Severino de Santa Teresa. O. C. D. "Biblioteca de la Presidencia de Colombia". Volumen 40 pág. 210 y siguientes. 
llamaban Juan González de Quevedo y Magdalena de Villegas. Ingresó en la Orden Franciscana, y tomó el hábito en el Convento de San Francisco, en Sevilla, en 1502 elegido definidor provincial, y en 1507 ministro provincial para el trienio que terminaba en 1510 .

Fue además guardián de Córdoba y de Granada (2).

El monarca español (Fernando el Católico) pensó en él para obispo de la diócesis proyectada de Santa María la Antigua del Darién y al mismo tiempo que se erigió fue designado su primer prelado (28 de agosto de 1513). El nombramiento Real había tenido lugar el 26 de julio anterior. El señor Quevedo recibió la consagración episcopal en Sevilla, de manos de su obispo fray Diego de Déza, O. P., el fiel amigo de Colón, a fines de 1513 o principios de 1514 (3).

Se embarcó para las Indias y arribó a la sede a fines de junio de 1514 , en la armada de Pedrarías Dávila, y tomó posesión el 30 del dicho mes. Ignoramos por qué no hizo antes la erección material del obispado (hoy diríamos decreto de ejecución) (4).

El obispo fue el alma de la nueva población y sabemos que en alguna ocasión en que enfermó el gobernador Pedrarias Dávila, el obispo quedó haciendo sus veces "por poder que de él tiene" (5).

El obispo venía con personal suficiente y con elementos necesarios para una diócesis. Es curioso estudiar lista de objetos "que los oficiales de Sevilla han de hacer comprar y proveer para el obispo Juan Quevedo, para las cosas del culto divino así para su persona como para la Iglesia de su diócesis" y que desde luego pagaría la corona. Veamos algunos, y por ello nos daremos cuenta de que venía muy bien provisto. "Seis altares y seis Aras; para manteles a los altares, sesenta varas. Para seis frontales de lienzo veinticinco varas, Para frontales de esos frontales de cada frontal tres varas de raso, con sus flocaduras de hilo... Doce palias para mudar, veinticuatro corporales... doce candeleros de azofar para el altar... doce vinajeras... seis misales romanos... veinticuatro amitos de lienzo, veinticuatro albas de lienzo: diez casullas... Un ornamento para las fiestas", etc., etc. Por el mismo estilo se especifican los ornamentos para el obispo, las alhajas (v. gr. "cinco cálices de plata con sus patenas, unas crismeras de plata, tres custodias de plata para poner el Sacramento, cuatro acetres de metal con sus hisopos") otros objetos necesarios, ya para el servicio de sacristán ("dos hierros para las hostias, tijeras para cortar hostias, un quintal de ceras para altares, tres quintales de aceite para las lámparas, cuatro linternas, seis campanillas de a libra, seis imágenes de lienzo, pintadas para retablos") ya para el rezo coral del oficio ("seis salterios, libros de canto toledano, y se añade "hace traer de Granada") (6).

Si de esta lista de objetos materiales pasamos al personal veremos que, dadas las circunstancias era satisfactorio.

(2) Id. p. 200.

(3) Id. p. 217.

(4) Id. p. 219.

(5) Id. p. 285.

(6) Id. p. 220 ss. 
Pudiéramos dividir el personal eclesiástico que vino con el obispo o fue llegando poco después, el clero secular y religiosos. En primer lugar se creó un Capítulo Catedral, compuesto de 10 miembros a saber: 4 dignidades, deán, arcediano, chantre y maestrescuela, y seis canónigos de oficio (7).

Además, tres sacerdotes para "Sacristanes Mayores" de la iglesia, y otro para "Arcipreste". Sabemos que en el libro de la "Armada" que llevó Pedrarías Dávila a tierra firme fueron con el obispo 13 clérigos: Toribio Cintado, García Rivero, Miguel Fernández, Juan de León, Diego Osorio (o Alvarez de Osorio) Gonzalo Alonso, Juan Ruíz de Guevara, Antón de Aranda, Juan de la Puente, Fernando de Luque, Pedro de Rosas, bachiller Villadiego, Juan de Buendía (8).

Viniendo más concretamente al Capítulo Catedral, el Senado del Obispo, trataremos de realizar su funcionamiento:

Deán (primera dignidad) Juan Pérez de Zalduendo, quien había estado antes en Santa María viajó a España en 1513 y regresó a principios de 1515.

Arcediano, Rodrigo Pérez.

Chantre Juan de León. Viajó a España y fue nombrado Diego Alvarez de Osorio.

Maestrescuela, Toribio Cintado (capellán del obispo) y luego Hernando de Luque (1521).

Canónigos. (Eran 6, pero no todos estuvieron durante todo el tiempo: Lorenzo, Martín, Leonel Gardín, Diego de Osorio, Gonzalo Alonso, Bartolomé de Bastidas, Francisco de Arroyo, Rodrigo de Prado, Andrés de Vera, Juan Martín, Cristóbal de Valencia (9).

Como se ve, había un personal no pequeño. Había además otros sacerdotes:

$\mathrm{Si}$ indagamos acerca de las comunidades religiosas, encontraremos que los franciscanos tenían un convento en Santa María la Antigua, y que además de los religiosos que allí laboraban, el obispo llevó consigo algunos más.

En 1512, dos años antes de la llegada del obispo, ya había convento de los hijos de Asís, pues a fines de ese año algunos conquistadores quisieron alzarse contra Balboa, este los aprehendió: y al ser libertados "Se acogieron al Monasterio de San Francisco, en que había tres o cuatro padres de aquella Orden". El superior era el padre Domingo, o Diego de la Torre, de quien sus contemporáneos hacen grandes elogios. Viajó a España para asistir a un capítulo hacia 1516 (10).

Si estudiamos la parte material de la vida religiosa de Santa María la Antigua, encontraremos que tenía catedral, que llevaba como titular la de la ciudad y en donde se veneraba una devota imagen, copia de la de

(7) Id. p. 247.

(8) Id. p. 248

(9) Id. p. 362 .

(10) Id. D. $419-421$. 
Sevilla (11); había una ermita o iglesia dedicada a San Sebastián, en los extramuros de la ciudad (12); se construyó un hospital de caridad dedicado a Santiago, con cincuenta camas; que en él había drogas, boticario (un italiano), y todas las comodidades que se podían pedir a principios del siglo XVI (13).

Si recorremos la Historia documentada de la iglesia de Urabá y Darién por nuestro colega reverendo padre fray Severino de Santa Teresa, veremos que había numerosos vecinos españoles, que muchos habían viajado con sus esposas, y que entre estos se podían encontrar personas conocedoras de diferentes oficios y artes, de modo que se esperaba que Santa María fuera el centro civilizador de donde saldrían después expediciones a conquistar y civilizar a los indígenas de las comarcas circunvecinas (14), no son suposiciones, veamos hechos: el capitán Francisco Becerra hacia 1516 emprendió una expedición por las regiones del Sinú. Internose Becerra por camino que nadie supo cuál y al verse que no llegaba se dio por perdido (15),

Pedrarías envió una expedición a buscar a Becerra y en ella iba de capellán nada menos que Lorenzo Martín, futuro canónigo de Santa María. En una información de méritos de este sacerdote, la sexta pregunta que se hace a los testigos era la siguiente: "Item, si si sabe que fui la entrada que hizo el factor Juan de Tavira al río Grande, donde se ahogó, y estuvimos cuatro meses en aquella jornada donde ningún provecho se siguió a mí ni a los otros que esto se hallaron, sino mucho trabajo y mucho gasto a grandes peligros e hambre muchos días" (16).

El licenciado Gaspar de Espinosa, antes de partir de la Provincia de Natá a la de París, dice: "Hice confesar con el Padre Vicario de S. Francisco (Fr. Francisco de S. Román) que con nosotros fue, sin que ninguno faltó de todos que no se confesase antes de que de allí saliese: e después el día que nos partimos de Natá, que fue a 29 de junio de 1516 años, salida la gente al campo, antes que nos moviésemos para ir a nuestro camino, hicimos ciertos votos a Nuestra Señora e al Señor Santiago, e una plegaria, e tiramos nuestro camino en nombre de Dios. Estuvimos en el dicho Cacique Natá cuatro meses aguardando tiempo e la gente de socorro que de esta ciudad se nos había de enviar. En todo este tiempo algunos días hacía juntar algunos indios, que eran muchos, en la iglesia que alli teníamos hecha, e el padre vicario les predicaba, por una lengua intérprete, nuestra santa fe católica: aprovechaba mucho, porque los muchachos, e mujeres muchos de ellos pedían que las tornasen cristianos, que lo querían ser; que los gandules e indios mayores es cosa excusada si Dios no espira en ellos" (17).

Parecía que Santa María la Antigua iba a ser una cabeza de puente, usando una locución moderna, para ir cristianizando toda una provincia,
(11) Id. p. 368.
(12) Id. p. 497.
(13) Id. p. 465 ss.
(14) Id. p. 387.
(15) Id. p. 505.
(16) Id. p. 508.
(17) Id. p. 514. 
pero los españoles que habían quedado admirados con la vegetación tropical, con la abundancia de las aguas, no contaban con los peligros que ese trópico, y esa hermosa selva escondían.

Y la primera forma como ese enemigo invisible comenzó a acabar la ciudad, fueron las enfermedades, palúdicas probablemente, y la molestia de mosquitos y otras sabandijas que hacía imposible la vida tranquila para un europeo.

"Muchas personas cada día de hambre y enfermedades morían", dice Las Casas y poco después el obispo Quevedo se quejaba al Rey del poco clero que tenía y decía: (1515) "Quedaron estos pocos clérigos porque siete son muertos y cinco se fueron" (18). El reverendo padre fray Severino de Santa Teresa en un interesante artículo publicado en la Revista de misiones. de Bogotá, No 51, agosto de 1929 , página 353, al comentar lo que los historiadores de la "insalubridad del clima de S. María la Antigua, pues llegaron a morir hasta setecientos hombres en un mes", añade: "El clima de esta región no creo que sea tan deletereo. No se deberá esta anormalidad a que los indios envenenaron las aguas del río Tanela que pasaba por Santa María? En ningún historiador hemos visto esta indicación pero no parece desprovista de fundamento. Aun en épocas recientes los indios karibe - kunas - cuando han querido sacar de sus tierras los blancos o civilizados, se han valido de ese medio".

A la insalubridad del clima, a la persecución solapada de los indígenas, se vino a añadir un tercer factor, el político, para ayudar a la ruina de la ciudad. Conocidas por demás son las diferencias entre Balboa y Pedrarías. Este tenía cierta ojeriza a la ciudad fundada por el primero, y para crearle una rival fundó en 1519 la ciudad de Panamá. Durante todos esos años hubo diferencias y rencillas entre los dos conquistadores, y fray Juan de Quevedo se puso de parte de Balboa. Puede verse sobre el particular el capítulo XX de la citada obra del padre Severino. Pero el resultado fue que las relaciones entre el obispo y el gobernador Pedrarías se fueron poniendo cada día más difíciles, y el señor Quevedo creyó que la única manera de mejorar todo, sería un viaje de él a España, el que emprendió más o menos a mediados de 1519 ("cinco años he estado allá", dice el mismo) (19).

Pasó por Cuba "donde algunos días estuvo". Viajó luego hasta Barcelona, en donde estaba la corte de el entonces clérigo presbítero Bartolomé de Las Casas.

Sobre estos asuntos puede verse Décadas, de Herrera (Década II, libro IV. Cap. V), "Luego, dice el mismo autor el obispo (Quevedo) fue a un lugarejo donde pasaba a una legua de allí e cayó luego enfermo de calenturas y desde a tres días murió... La víspera de Navidad el 24 de diciembre de ese mismo año 1519" (20).

Murió lejos de su grey: sin haber podido arreglar en la Corte las dificultades que llevaba, aparentemente vencido y fracasado. Pero esas semi-

(18) Id. p. 248-288.

(19) Id. Tomo 41, p. 324 ,

(20) Id. D. $330-369$. 
llas que creemos fracaso, han sido siempre las que han producido a lo largo de la vida el fruto de vida eterna, como nos lo dice el Evangelio.

Cuando se supo en Santa María el fallecimiento del obispo, hacia el mes de marzo de 1520, los canónigos nombraron vicario capitular al deán Juan Pérez de Zalduendo. Este que era amigo de Pedrarías, fue extremadamente duro con los partidarios de Balboa, y así remitió con grillos a España al arcediano Rodríguez Pérez (21).

Pero era necesario pensar en un nuevo prelado, y el Rey presentó al Papa el nombre del religioso dominico fray Vicente Peraza. Nacido en Sevilla hacia 1489, hizo su profesión religiosa en San Pablo, de la misma Sevilla, el 5 de abril de. 1506. Estudió en San Pablo de Valladolid (1511) y luego fue prior de varios conventos en Andalucía (22).

Presentado por el Rey para obispo de Santa María la Antigua el 17 de mayo de 1520, fue nombrado por el Papa el 5 de diciembre del mismo año.

Las ejecutoriales le debieron ser enviadas hacia marzo de 1521, y se le pedía que se trasladara lo más pronto que fuera posible a la sede.

En Burgos y con fecha $1^{9}$ de diciembre de 1521, hizo la erección material de la diócesis, la ejecución en nuestro actual lenguaje, que como hemos visto no había ejecutado el obispo Quevedo (23).

Pero después marchó para Santa María el clérigo licenciado Hernando de Zelaya, en compañía del arcediano Rodrigo Pérez, quien había sido absuelto en España, restituído a su puesto y con orden de que se le reconocieran los salarios del tiempo de su ausencia. El licenciado Zelaya traía un poder del obispo para que en su nombre tomara posesión de la diócesis. Llegaron a Santa María el $1^{\circ}$ de julio de 1522, y poco después tuvo lugar la toma de posesión. Con esta toma cesó en sus funciones el deán Pérez de Zalduendo, quien fue remplazado por el arcediano Rodrigo Pérez, el que había sido enviado preso, y comenzó a regir los destinos de la diócesis como gobernador del obispado (24).

Mientras tanto, Pedrarías trabajaba activamente ante la corte para que se pasara la gobernación y la diócesis a la ciudad de Panamá, su querida fundación y para ello hacía resaltar los inconvenientes de Santa María: su insaluble clima, las dificultades de estar alejada del mar, etc.

El obispo Peraza se consagró en España, y vino a Santa María a donde llegó a principios de marzo de 1524. Nombró provisor al maestrescuela Hernando de Luque; pero ya para entonces Pedrarías había trasladado a Panamá los vecinos y enseres de Santa María (25). Unos tres meses después de su llegada el señor Peraza "con el título y clero y aparato se retiró a Panamá" y falleció allí, misteriosamente, y se susurró que envenenado, hacia septiembre del mismo año de 1524 (26).

(21) Id. p. 355 .

(22) Tomo 40, p. 340.

(23) Id. Tomo 41.

(24) Id. Tomo 41, p. 359.

(25) Id. p. 360.

(26) Id. p. $370-377$. 
Podríamos decir de Santa María la Antigua lo que siglos después dijo nuestro poeta Rivera, de Arturo Cova "La devoró la selva". Pero, como dice el padre Severino en su citado artículo de la Revista de misiones, "Si sabemos donde estaba situada, sus ruinas aún no han desaparecido aunque si están ocultas por la maleza todavía fácilmente se descubren los pisos enladrillados de algunos edificios que seguramente serían la Catedral, el Palacio Episcopal, la casa de Pedrarías Dávila, etc. Esta ciudad madre nunca se ha convertido en esos pueblecillos miserables de pescadores". Tal es la trágica historia de la primera ciudad que, según el plan de Fernando el Católico, debía ser el centro de donde habían de irradiar por toda una extensa comarca la Cruz del Salvador y la civilización castellana. 